\title{
Estimating the alcohol-breast cancer association: a comparison of diet diaries, FFQs and combined measurements
}

\author{
Ruth H. Keogh • Jin Young Park • Ian R. White - Marleen A. H. Lentjes • \\ Alison McTaggart • Amit Bhaniani - Benjamin J. Cairns - Timothy J. Key • \\ Darren C. Greenwood • Victoria J. Burley • Janet E. Cade · Christina C. Dahm • \\ Gerda K. Pot • Alison M. Stephen · Gabriel Masset • Eric J. Brunner • \\ Kay-Tee Khaw
}

Received: 21 November 2011/Accepted: 8 May 2012/Published online: 29 May 2012

(C) The Author(s) 2012. This article is published with open access at Springerlink.com

\begin{abstract}
The alcohol-breast cancer association has been established using alcohol intake measurements from Food Frequency Questionnaires (FFQ). For some nutrients diet diary measurements are more highly correlated with true intake compared with FFQ measurements, but it is unknown whether this is true for alcohol. A case-control study (656 breast cancer cases, 1905 matched controls) was sampled from four cohorts in the UK Dietary Cohort Consortium. Alcohol intake was measured prospectively using FFQs and 4- or 7-day diet diaries. Both relied on fixed portion sizes allocated to given beverage types, but those used to obtain FFQ measurements were lower. FFQ measurements were therefore on average lower and to enable fair comparison the FFQ was "calibrated" using diet diary portion sizes. Diet diaries gave more zero measurements, demonstrating the challenge of distinguishing
\end{abstract}

R. H. Keogh $(\bowtie) \cdot$ I. R. White

MRC Biostatistics Unit, Institute of Public Health,

University Forvie Site, Robinson Way, Cambridge, UK

e-mail: ruth.keogh@mrc-bsu.cam.ac.uk

R. H. Keogh - M. A. H. Lentjes - A. McTaggart - A. Bhaniani · K.-T. Khaw

MRC Centre for Nutritional Epidemiology in Cancer Prevention and Survival, Department of Public Health and Primary Care,

University of Cambridge, Cambridge, UK

\section{J. Y. Park}

Section of Nutrition and Metabolism, International Agency

for Research on Cancer, Lyon, France

\section{B. J. Cairns · T. J. Key}

Cancer Epidemiology Unit, University of Oxford, Oxford, UK

D. C. Greenwood · V. J. Burley · J. E. Cade

Centre for Epidemiology and Biostatistics, University of Leeds,

Leeds, UK never-from episodic-consumers using short term instruments. To use all information, two combined measurements were calculated. The first is an average of the two measurements with special treatment of zeros. The second is the expected true intake given both measurements, calculated using a measurement error model. After confounder adjustment the odds ratio (OR) per $10 \mathrm{~g} /$ day of alcohol intake was 1.05 (95\% CI $0.98,1.13)$ using diet diaries, and $1.13(1.02,1.24)$ using FFQs. The calibrated FFQ measurement and combined measurements 1 and 2 gave ORs $1.10(1.03,1.18), 1.09(1.01,1.18), 1.09$ $(0.99,1.20)$, respectively. The association was modified by HRT use, being stronger among users versus non-users. In summary, using an alcohol measurement from a diet diary at one time point gave attenuated associations compared with FFQ.

\author{
C. C. Dahm \\ Department of Cardiology, Aarhus University Hospital, Aalborg, \\ Denmark \\ C. C. Dahm \\ Department of Epidemiology, School of Public Health Aarhus \\ University, Aarhus, Denmark \\ G. K. Pot - A. M. Stephen \\ MRC Human Nutrition Research, Elsie Widdowson Laboratory, \\ Cambridge, UK \\ G. Masset - E. J. Brunner \\ Department of Epidemiology and Public Health, University \\ College London, London, UK
}


Keywords Breast cancer - Alcohol - Food frequency questionnaire · Diet diary · Case-control study · Measurement error

\section{Introduction}

Breast cancer is the most common type of cancer in women worldwide [1] and several large studies and meta-analyses have concluded that increased breast cancer risk is associated with higher alcohol intake [2-12]. Breast cancer has been added to the list of cancers for which there is convincing evidence of a causal relationship with alcohol consumption by the International Agency for Research on Cancer (IARC) [13] and World Cancer Research Fund/ American Institute for Cancer Research 2007 report [11].

The exposure of interest in nutritional epidemiology is typically the long term average or 'usual' daily intake of a given nutrient or food group. It is not feasible to observe true exposure and studies rely on self-reported measures of intake. Food frequency questionnaires (FFQs) are the most widely used dietary assessment instrument in large observational studies of adults; these are structured questionnaires listing varying numbers of foods, and individuals report how often they consume each item from a range of frequency options, considering their intake over a period such as the previous several months or year [14]. Limitations of FFQs are that they are restricted to listed food items and most often do not record detailed portion size information. Other dietary assessment instruments include 24-h recalls, which ask individuals to report their intake on the previous day and are often conducted by interview, and diet diaries, on which individuals record all their intake over a period of several days. These instruments provide more detailed information than FFQs but provide a "snapshot" of intake over a short time period which is assumed to reflect a habitual pattern. Because of their expense, 24-h recalls and diet diaries have been used mainly as validation tools in large cohorts rather than as the main instrument. Error in self-reported measurements of dietary intake is a major problem in nutritional epidemiology, resulting in biased, typically attenuated, estimated diet-disease associations [15]. Some studies have quantified the error in FFQ and diet diary or 24-h recall measurements by comparison with objective recovery biomarkers, which provide unbiased measures of true intake but of which there are very few. Validation studies using recovery biomarkers for protein, potassium and total energy intake have found diet diary or 24-h recall measurements to be more highly correlated with the biomarkers, and with the underlying but unobserved 'true intake' using measurement error modelling, compared with FFQs [16-18]. For nutrients for which there is no recovery biomarker, results from using FFQs and diet diaries have been compared in case-control studies within cohorts. A study of fibre intake and colorectal cancer in the UK Dietary Cohort Consortium found a significant inverse association using diet diary data but not using FFQ data [19]. Two studies have observed significant positive associations between fat intake and breast cancer using diet diary but not FFQ data [20, 21], though a recent study found no association using either instrument [22].

What is not yet known is whether diet diaries provide a less error prone measure of intake for 'episodically consumed' items, such as alcoholic drinks, compared with FFQs, in the absence of recovery biomarkers. Episodically consumed foods are those which are not consumed every day by many individuals, and another example is fish; this is in contrast to nutrients such as fat which will be consumed daily because of their dispersion among many foods. Episodically consumed items may not be recorded in short term records such as diet diaries. In the case of alcohol there is also the issue that some individuals are never-consumers. Where zero intake is recorded in a diet diary from one time point, it is not possible to distinguish between episodic- and never-consumers. FFQs do not, at least in theory, suffer from this issue. On the other hand, diet diaries collect much more detailed information on alcohol intake for individuals reporting non-zero intake compared with FFQs.

In this paper we compare, for the first time, the association between alcohol intake and breast cancer using data from both FFQs and 4- or 7-day diet diaries obtained in the UK Dietary Cohort Consortium, which has pooled data from matched case-control studies of breast cancer sampled within four UK cohort studies from which nutritional data were available from both diet diaries and FFQs. Measurements of alcohol intake from both instruments rely on fixed portion sizes and to deal with this, the FFQ was "calibrated" using diet diary portion sizes. We also propose two measurements which combine FFQ and diet diary information. It has been suggested that the alcohol-breast cancer association may be modified by hormone replacement therapy (HRT) use, menopausal status, and folate intake. Interactions between alcohol intake and these variables are also investigated.

\section{Methods}

Study population

Individual participant data were pooled from matched casecontrol studies of breast cancer sampled from four studies in the UK Dietary Cohort Consortium [19]: EPIC-Norfolk, EPIC-Oxford, the UK Women's Cohort Study (UKWCS) 
Table 1 Summary of studies in the UK Dietary Cohort Consortium case-control study of breast cancer

\begin{tabular}{llllll}
\hline Study & $\begin{array}{l}\text { Number of } \\
\text { cases/controls }\end{array}$ & $\begin{array}{l}\text { Age range at } \\
\text { diary completion }\end{array}$ & $\begin{array}{l}\text { Mean age } \\
\text { at diagnosis }\end{array}$ & $\begin{array}{l}\text { Date range of } \\
\text { diary completion }\end{array}$ & $\begin{array}{l}\text { Last date of } \\
\text { follow-up }\end{array}$ \\
\hline EPIC-Norfolk & $353 / 1252$ & $40-78$ & $65.0(9.0)$ & Feb 1993-Apr 98 & 31 March 2010 \\
EPIC-Oxford & $194 / 194$ & $23-88$ & $56.9(11.0)$ & Feb 1993-Apr 99 & 31 Dec 2006 \\
UKWCS & $41 / 196$ & $40-75$ & $59.1(9.4)$ & May 1999-Feb 02 & 31 March 2006 \\
Whitehall II & $68 / 263$ & $39-61$ & $58.3(6.5)$ & Sep 1991-Apr 93 & 30 Sept 2005 \\
\hline
\end{tabular}

and Whitehall II. The individual cohorts and methods of dietary assessment have been described elsewhere [23-28]. The MRC National Survey of Health and Development is also part of the UK Dietary Cohort Consortium, but was excluded from this analysis because it provided diet diary but not FFQ measurements [29]. Each cohort collected dietary information using 7-day (EPIC-Norfolk, EPICOxford, Whitehall II) or 4-day (UKWCS) diet diaries completed on consecutive days at recruitment to the study. FFQs were administered just before or concurrently with the diaries. Anthropometric measurements and lifestyle factors were collected by trained researchers or in questionnaires administered prior to or concurrently with the dietary assessments. The studies are summarised in Table 1 .

\section{Selection of cases and controls}

Breast cancer cases were women free of cancer (except non-melanoma skin cancer) at the date of diary commencement and who developed breast cancer at least 6 months after that date, but before the end of the study period (Table 1). Incident cases (International Statistical Classification of Diseases and Related Health Problems 9th and 10th revision: codes 174, C50) were ascertained by record linkage with local cancer registries and the UK Office for National Statistics.

Within studies, each case was matched to up to five controls based on age at recruitment ( \pm 3 years) and date of diary completion ( \pm 3 months). Controls were required to be free of all cancer (except non-melanoma skin cancer) at the date of diary commencement and free of breast cancer at the end of follow-up. In all studies apart from UKWCS, controls were required to have at least as much follow-up time as their case, with the exception of a small number of cases in EPIC-Norfolk where this condition was relaxed to obtain sufficient controls. The data from EPIC-Oxford were restricted to women who were non-users of HRT, because the data originated from an existing case-control sample.

A small number of individuals did not have FFQ measurements and were excluded (46 EPIC-Norfolk, 3 UKWCS, 8 Whitehall II). This investigation is based on 656 breast cancer cases and 1905 matched controls.
Dietary assessment

FFQs are structured questionnaires designed to measure 'habitual' intake and completers were asked to consider their dietary intake over the past year. EPIC-Norfolk and EPICOxford used the same FFQ while those used in Whitehall II and UKWCS differed slightly. The FFQs used by EPICNorfolk, EPIC-Oxford and Whitehall II asked individuals to report one of 9 frequencies of intake for each food item: never or less than one/month, 1-3/month, once a week, 2-4/week, 5-6/week, once a day, 2-3/day, 4-5/day, 6+/day. UKWCS divided the lowest category of consumption into "never" and "less than one/month", and the other categories were as above. For each food item a portion size is stated on the questionnaire; these are mostly non-specific (e.g. a 'medium serving'). To obtain continuous measurements of food intakes the FFQ software program assigned a portion size (e.g. in grams) to each item, which is combined with the frequency of intake to give a measurement of intake. In EPICNorfolk the following frequencies of intake per day were assigned to the 9 categories of intake detailed above: $0,1 / 14$, $1 / 7,3 / 7,5.5 / 7,1,2.5,4.5,6$. The frequencies used for each response category differed only slightly in other studies.

In the diet diary participants were asked to record in detail all the foods and beverages they consumed at designated times throughout the day, usually as prompted by time slots (e.g. breakfast, mid-morning, evening meal). Descriptions of how to report portion size were provided. Participants were not specifically instructed to weigh or measure their items, though for some items it was suggested that amounts could be reported by volume. A series of photographs were also provided showing small, medium and large portions of a range of commonly eaten foods.

Diet diaries were coded to give nutrient and food group intakes using the Data into Nutrients for Epidemiological Research (DINER) program developed in EPIC-Norfolk [30], with the exception of UKWCS food diaries which were pre-coded using the Diet And Nutrition Tool for Evaluation (DANTE) program [31]. We compared 100 food diaries coded under both programs and found good agreement for most nutrients, though the geometric mean intake of alcohol from DINER was $7 \%$ higher $(95 \%$ $\mathrm{CI}=3-11 \%)$ than from DANTE. 
Assessment of alcohol intake

The EPIC-Norfolk and EPIC-Oxford FFQ included questions on consumption of four types of alcoholic beverage: "wine (glass)", "beer, lager or cider (half pint)", "port, sherry, vermouth, liqueurs (glass), "spirits, e.g. gin, brandy, whisky, vodka (single)". The UKWCS FFQ separated beer/lager from cider and the Whitehall II FFQ

Table 2 Summary of portion sizes used in FFQ and diet diary measurement calculations

\begin{tabular}{|c|c|c|c|c|}
\hline \multicolumn{2}{|l|}{ Study centre } & \multicolumn{2}{|l|}{$\begin{array}{l}\text { Program-assigned } \\
\text { portion size }(\mathrm{ml})\end{array}$} & $\begin{array}{l}\text { Assigned alcohol } \\
\text { per } 100 \mathrm{ml}(\mathrm{g})\end{array}$ \\
\hline \multicolumn{5}{|c|}{ A. FFQ: Program-assigned portion size and amount of alcohol per $100 \mathrm{ml}$ for each alcoholic beverage type } \\
\hline \multicolumn{5}{|c|}{ EPIC-Norfolk, EPIC-Oxford } \\
\hline Wine & & 125 & & 8.7 \\
\hline Beer/lager/cider & & 288 & & 3.93 \\
\hline Spirits & & 23 & & 31.7 \\
\hline Fortified wine/liqueurs & & 50 & & 13.15 \\
\hline \multicolumn{5}{|l|}{ Whitehall II } \\
\hline Wine & & 125 & & 9.1 \\
\hline Beer/lager/cider & & 287 & & 2.5 \\
\hline Spirits & & 23 & & 31.7 \\
\hline Fortified wine & & 48 & & 15.9 \\
\hline Liqueurs & & 25 & & 18.66 \\
\hline \multicolumn{5}{|l|}{$W K W C S$} \\
\hline Wine & & 125 & & 9.25 \\
\hline Beer/lager/cider & & 287 & & 3.08 \\
\hline Spirits & & 23 & & 31.7 \\
\hline Fortified wine/liqueurs & & 40 & & 16.65 \\
\hline Diet Diary program & $\begin{array}{l}\text { Program-assigned } \\
\text { non-specific portion } \\
\text { size }(\mathrm{ml})\end{array}$ & $\begin{array}{l}\text { Mean }(\mathrm{SD}) \text { alcohol } \\
\text { per } 100 \mathrm{ml}(\mathrm{g})\end{array}$ & $\begin{array}{l}\text { Average portion } \\
\text { size }(\mathrm{ml})^{\mathrm{a}}\end{array}$ & $\begin{array}{l}\text { Average } \\
\text { alcohol }(\mathrm{g}) \text { per } \\
\text { average portion size }\end{array}$ \\
\hline
\end{tabular}

B. Diet diary: Program-assigned non-specific portion size and average amount of alcohol per $100 \mathrm{ml}$ for each alcoholic beverage type. Average portion size and corresponding average amount of alcohol per average portion size were used to obtain the calibrated FFQ measurements

\begin{tabular}{|c|c|c|c|c|}
\hline Wine & 175 & $8.76(1.53)$ & 173.4 & 15.2 \\
\hline Beer/lager & 284.5 & $3.31(0.95)$ & $284.5^{\mathrm{b}}$ & $9.4^{\mathrm{c}}$ \\
\hline Cider & 284.5 & $4.23(1.74)$ & $284.5^{\mathrm{b}}$ & $12.0^{\mathrm{c}}$ \\
\hline Spirits & 37.5 & $30.53(1.04)$ & 42.6 & 13.0 \\
\hline Fortified wine & 63 (sherry) & $14.63(1.36)$ & 51.9 & $7.6^{\mathrm{d}}$ \\
\hline & \multicolumn{4}{|c|}{75 (other fortified wine) } \\
\hline Liqueurs & 37.5 & $22.23(7.63)$ & 42.3 & $9.5^{\mathrm{d}}$ \\
\hline \multicolumn{5}{|c|}{ DANTE (UKWCS) } \\
\hline Wine & 125 & $9.32(0.58)$ & 125 & 11.7 \\
\hline Beer/lager & 287 & $3.19(1.18)$ & $287^{\mathrm{b}}$ & 9.0 \\
\hline Cider & 287 & $3.76(0.05)$ & $287^{\mathrm{b}}$ & 10.7 \\
\hline Spirits & 23 & $30.88(0.99)$ & 23 & 7.0 \\
\hline Fortified wine & 50 & $14.65(1.52)$ & 50 & $7.3^{\mathrm{d}}$ \\
\hline Liqueurs & 25 & $21.50(6.16)$ & 25 & $5.5^{\mathrm{d}}$ \\
\hline
\end{tabular}

${ }^{a}$ It was not possible to calculate average portion size using DANTE data. This was because the available data gave the total amount consumed in $\mathrm{ml}$ and corresponding amount of alcohol per day and by beverage type, but was not in general broken down into individual drinks as in DINER data. Assigned portion sizes in these data were strongly dominated by the non-specific portion sizes

${ }^{b}$ It was not necessary to calculate an average portion size for beer and cider because a half pint measure was specified on the FFQ

c The average proportion of beer plus cider intake which was beer was 0.82

${ }^{\mathrm{d}}$ The average proportion of fortified wine and liqueur intake which was fortified wine was 0.84 in both DINER and DANTE data 
separated liqueurs from fortified wine. The portion sizes assigned to each beverage type [in millilitres (ml)] are shown in Table 2A alongside the strength assumed for each beverage type (in grams of alcohol per $100 \mathrm{ml}$ ). Portion sizes and assumed strength differed somewhat across studies and we did not standardise them; these figures were used in conjunction with the reported frequencies of intake to calculate average alcohol amount per day for each beverage. These were summed across beverage types to give average daily total alcohol intake in g/day.

In the diet diary data used for this study, alcoholic drinks were divided into six categories: wine, beer/lager, cider, fortified wine, liqueurs, spirits. In the diet diaries, measured portions (e.g. in ml) were rarely reported and instead descriptive terms were used (e.g. 'small glass', 'measure'), with the exception of beer, where pints, or parts thereof, were reported. The descriptive terms were used to assign a portion in DINER (e.g. 'wine glass'), and where it was reported the relative size, i.e. small (S), medium (M) or large (L); or, where not specified, a non-specific (n.s.) portion size was assigned. Non-specific portion sizes were typically taken to be a 'medium' portion. Many individuals did not give detail about the relative portion size. For example in the DINER data $86 \%$ of wine drinkers always reported wine in a wine glass, of which $84 \%$ were assigned a non-specific wine glass on every occasion this item was reported in the diet diary. The following portions appeared in the data: bottle (S, n.s.), can (S, L, n.s.), vending size cup (n.s.), dash, dessertspoon, glass ( $, \mathrm{M}, \mathrm{L}$, n.s.), sherry glass (S, M, L, n.s.), tumbler (S, M, L, n.s.), wine glass (S, M, L, n.s.), mug, sprinkle, tablespoon, teaspoon, alcohol measure (at home, in the pub, n.s.), mouthful, unknown portion. The DANTE program has a much less extensive range of built-in portions, and nonspecific portion sizes were assigned in many cases. For example, it was not possible to tell whether a recorded portion of $125 \mathrm{ml}$ of wine was assigned because the glass size was not specified or because the individual reported intake in millilitres. In both DINER and DANTE an amount in millilitres was assigned to each portion and the corresponding amount of alcohol was calculated using information about the drink consumed. Total alcohol consumed over the course of the diet diary was divided by the number of days over which it was completed to estimate average daily alcohol intake in g/day. The non-specific portion sizes and average amounts of alcohol assigned per $100 \mathrm{ml}$ for each beverage type, under each data-entry program (DINER, DANTE), are summarised in Table 2B.

For a given beverage the non-specific portion size assigned in the DINER program tended to be larger than the FFQ portion size, with the exception of 'beer', the only beverage for which a measured portion size was referred to on the FFQ (half pint), while this was not in general the case in the DANTE program. To enable a fair comparison between the two dietary assessment instruments, we "calibrated" the FFQ measurements using portion sizes derived from diet diary measurements. This was done separately for each beverage type listed on the FFQ. For diet diaries coded using DINER, we calculated the average diet diary portion size for each beverage type (excluding measures assumed to refer to alcohol used in cooking, such as 'dash') and the corresponding average amount of alcohol (drink strength). For diet diaries coded using DANTE the available data was such that it was not possible to calculate average portion sizes, so the average amount of alcohol per non-specific portion size was calculated. For beer and cider, which are combined on the FFQ (except in UKWCS) but not in the diet diary data, we used the average proportion of total beer and cider intake that was beer alone and that was cider alone to estimate an average amount of alcohol per half pint of beer and cider combined. A similar procedure was followed for fortified wine and liqueurs, which were combined on the FFQ (except in Whitehall II) but not in the diet diary data. The above calculations were performed separately by study using information summarized in the last two columns of Table 2B. For each beverage type, the calibrated FFQ measurement was calculated by multiplying the alcohol amount per calibrated portion size by the frequency reported in the FFQ. Total alcohol intake was calculated as the sum of alcohol from all beverage types.

\section{Statistical analysis}

Associations between alcohol intake and breast cancer were investigated first using FFQs and diet diaries separately, followed by the calibrated FFQ measurements, using the models described below.

We also propose a combined measure of alcohol intake using calibrated FFQ and diet diary measurements, devised to take advantage of both measurements, including that FFQs are likely to capture never-consumers more reliably. Figure 1 shows scatter plots of FFQ and calibrated FFQ measurements against diet diary measurements, showing no evidence of systematic differences between the latter pair. To obtain the combined measurement, individuals with a measurement of zero alcohol intake on both the FFQ and the diet diary were assigned a combined measurement of zero (476 individuals). Those with a measurement of zero on the diary but greater than zero on the FFQ were assigned their calibrated FFQ measurement (333 individuals), and vice versa (135 individuals). Those with nonzero measurements from both the FFQ and the diary were assigned the mean of their calibrated FFQ and diary measurements (1617 individuals). This is referred to as combined measurement 1 . 
Fig. 1 Scatter plots of FFQ and calibrated FFQ measurements against diet diary measurements of alcohol intake
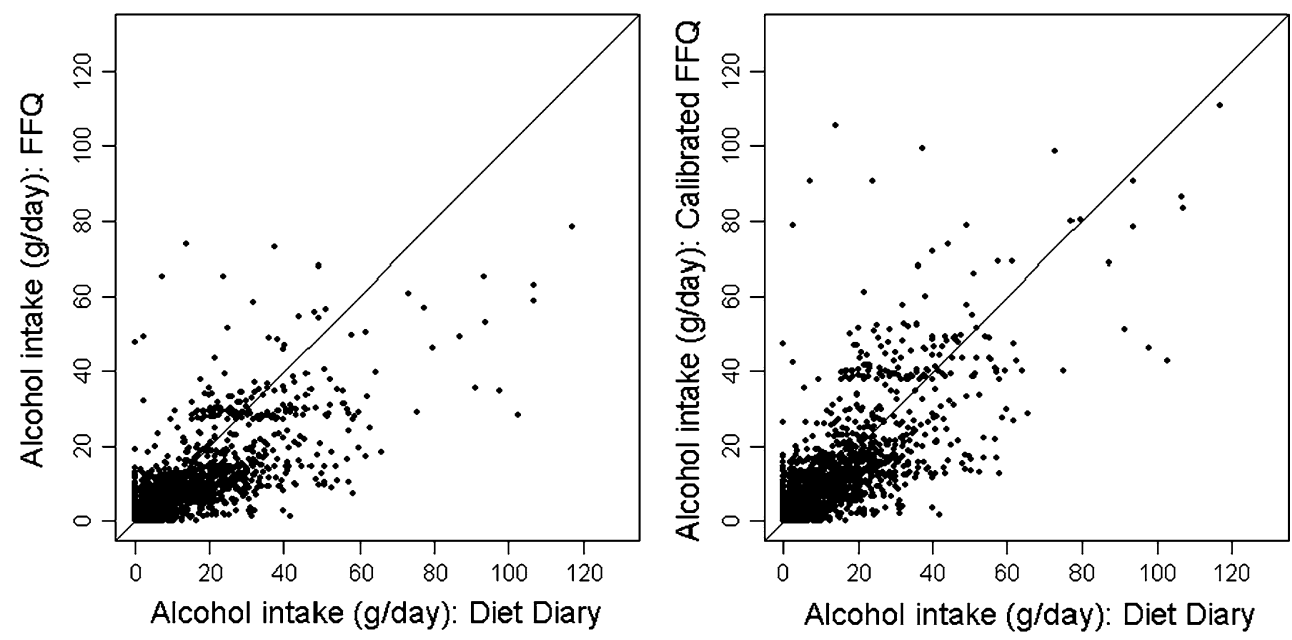

Repeated 7-day diary measurements of alcohol intake were available for 281 women (62 cases, 219 controls) in EPIC-Norfolk from a second time point. This enabled us to use measurement error modelling to correct for bias in OR estimates found using diet diary measurements from one time point. We fitted the "never and episodic consumers model' [32] to the diet diary data with adjustment using FFQ measurements. This model takes into account the special issues associated with zero measurements in diet diary data. For the covariate-adjusted diet-disease model described below, the variables used in the multivariable model were also adjusted for in the measurement error model. This procedure resulted in an estimate of 'expected true intake' for each individual, conditional on both diet diary and FFQ data and, in the case of the multivariable model, also on individual characteristics. Using regression calibration [33], which is well established technique for measurement error correction, the expected true intake values were used in the regression models described below to obtain corrected estimates of association. The expected true intake is in essence a combined measure based on the observed dietary data and we refer to it as combined measure 2. Note that because this method gives an expected value for true intake it does not assign values of zero.

The data across all studies was pooled and conditional logistic regression models were used to estimate odds ratios (ORs) and $95 \%$ confidence intervals (CI) for breast cancer risk according to alcohol intake, with and without adjustment for potential confounders. This corresponds to a fixed-effect meta-analysis. Heterogeneity in the association across study centres was assessed using the $\mathrm{I}^{2}$ statistic [34]. We present ORs per $10 \mathrm{~g} /$ day increase in alcohol intake, approximately equivalent to 1 Unit, and compare ORs found using diet diary, FFQ, calibrated FFQ and the two combined measurements. ORs within categories of intake are also presented, except for combined measurement 2, since the method of regression calibration does not extend to allow categorization of the expected value. Tests for the difference between FFQ and diet diary estimates were performed by estimating the standard error of the difference between log OR estimates from the two different regressions using bootstrapping. Non-linearity in the association was investigated by including squared terms for the alcohol measurement in the regression.

A multivariable model adjusted for exact age, parity, height, weight, HRT use at baseline, physical activity, menopausal status, smoking status, education level, and energy and folate intake measured using the diet diary. Multiple imputation was used to handle missingness in adjustment variables using 10 imputed data sets $(12 \%$ of individuals were missing data in one or more of the above variables). Family history of breast cancer was missing completely in EPIC-Oxford and Whitehall II, and social class was missing completely in EPIC-Oxford. These variables were adjusted for in a sensitivity analysis. Wald tests were used to test for interactions of alcohol intake with HRT use, menopausal status and folate intake.

All statistical tests were two sided, and all statistical analyses were performed using Stata version 10 (Stata Corporation, College Station, TX, USA), except the never and episodic consumers model which was fitted in $\mathrm{R}$. Multiple imputation was performed using the 'ice' [35] and 'mim' [36] packages in Stata.

\section{Results}

Measurements of alcohol intake

Table 3 summarizes alcohol intake measures obtained using diet diary, FFQ, calibrated FFQ and the combined 
Table 3 Summary of alcohol intake measured using diet diary, FFQ, calibrated FFQ, and combined measurements, among all individuals, by case-control status, and by study centre

\begin{tabular}{|c|c|c|c|c|c|c|c|c|}
\hline & \multicolumn{3}{|c|}{$\%$ Reporting 0 intake } & \multicolumn{5}{|c|}{ Mean (SD) alcohol intake in g/day } \\
\hline & Diet diary & FFQ & $\begin{array}{l}\text { Combined } \\
\text { measurement } 1\end{array}$ & Diary & FFQ & Calibrated FFQ & $\begin{array}{l}\text { Combined } \\
\text { measurement } 1\end{array}$ & $\begin{array}{l}\text { Combined } \\
\text { measurement } 2\end{array}$ \\
\hline \multicolumn{9}{|l|}{ All individuals } \\
\hline Total alcohol & 32 & 24 & 19 & $9.3(13.2)$ & $6.3(9.3)$ & $8.5(12.6)$ & $9.2(12.1)$ & 8.5 (11.4) \\
\hline Wine & 51 & 31 & 28 & $5.7(9.7)$ & $4.0(7.2)$ & $5.4(9.8)$ & $5.9(9.1)$ & - \\
\hline Beer/lager/cider & 79 & 73 & 67 & $0.96(3.4)$ & $0.77(2.9)$ & $0.72(2.7)$ & $0.98(2.9)$ & - \\
\hline Spirits & 77 & 64 & 61 & $1.7(5.4)$ & $0.91(2.7)$ & $1.6(4.6)$ & $1.9(4.9)$ & - \\
\hline Fortified wine/liqueurs & 75 & 65 & 59 & $0.91(2.4)$ & $0.61(1.7)$ & $0.82(2.3)$ & $1.0(2.3)$ & - \\
\hline Controls: total alcohol & 33 & 25 & 20 & $8.9(13.0)$ & $5.9(8.9)$ & $8.0(12.0)$ & $8.7(11.7)$ & $8.1(11.2)$ \\
\hline Cases: total alcohol & 27 & 20 & 16 & $10.5(13.7)$ & $7.4(10.3)$ & $10.1(14.1)$ & $10.5(13.0)$ & $9.7(12.0)$ \\
\hline \multicolumn{9}{|l|}{ Study centre: total alcohol } \\
\hline EPIC-Norfolk & 35 & 26 & 21 & $8.2(12.2)$ & $5.7(8.9)$ & $7.9(12.2)$ & $8.3(11.5)$ & $7.2(10.7)$ \\
\hline UKWCS & 32 & 19 & 16 & $8.6(10.5)$ & $6.6(8.4)$ & $6.7(8.5)$ & $8.1(8.8)$ & $9.4(9.8)$ \\
\hline EPIC-Oxford & 25 & 21 & 16 & $11.0(13.6)$ & $7.4(10.0)$ & $9.9(13.5)$ & $10.6(12.4)$ & $10.6(11.7)$ \\
\hline Whitehall II & 25 & 20 & 14 & $13.0(17.6)$ & 7.8 (10.6) & $11.1(15.0)$ & $12.3(15.6)$ & $11.8(14.1)$ \\
\hline
\end{tabular}

measurements. The number of women assigned zero intake was higher on the diet diary than the FFQ, which, as discussed in the introduction, was expected because of the short term nature of this instrument. Combined measurement 1 naturally gave the lowest number of zeros. Both mean alcohol intake and the proportion of individuals assigned non-zero consumption were higher among cases than controls. Intake differed somewhat across the casecontrol samples from the four study centres. The EPICNorfolk sample contained the highest proportion of individuals assigned zero intake for both FFQ and diet diary, and Whitehall II the lowest.

\section{Participant characteristics and alcohol intake}

Table 4 presents participant characteristics in categories of alcohol intake according to combined measurement 1 . We chose to use combined measurement 1 here since it is a simple and intuitive combination of the two available measurements. As noted earlier, combined measurement 2 does not assign any values of zero intake. Individuals assigned zero intake using combined measurement 1 tended to weight more, were less physically active, had lower level of education, were of lower social class, and were more likely to be postmenopausal but less likely to be users of HRT. Heavier drinkers were younger, taller, and more likely to have no children and to be smokers. Energy intake increased with higher alcohol consumption, while there was no difference in folate intake across categories of alcohol intake. Family history of breast cancer was not associated with alcohol intake.
Alcohol intake and breast cancer

Figure 2 shows adjusted OR estimates within studies using combined measurement 1 : there is no evidence of heterogeneity between studies $\left(\mathrm{I}^{2}=0.0 \%\right)$. All studies apart from UKWCS showed a positive association between alcohol intake and breast cancer risk. Because of its size UKWCS sample did not make a large contribution to the pooled estimate. All subsequent results were based on a pooled, i.e., fixed-effect, analysis. Table 5 shows OR estimates per $10 \mathrm{~g} /$ day increase in alcohol intake and within categories of intake. The OR per $10 \mathrm{~g} /$ day increase in total alcohol intake found using FFQ measurements (unadjusted: OR 1.15 (95\% CI 1.05,1.26), adjusted: 1.13 (95\% CI 1.02,1.24)) was higher than that found using diet diary measurements (unadjusted: 1.07 (95\% CI 1.00,1.15), adjusted: 1.05 (95\% CI 0.98,1.13)).

Very similar estimates were found using the calibrated FFQ (adjusted OR 1.09 (95\% CI 1.02,1.17)), combined measurement 1 (adjusted OR 1.09 (95\% CI 1.01,1.17)) and combined measurement 2 (adjusted OR 1.09 (95\% CI $0.99,1.20)$ ). There was a significant difference between the OR estimates found using FFQ and diet diary measurements ( $p$ value 0.028 ) and between calibrated FFQ and diet diary estimates ( $p$ value 0.047 ).

Additional adjustment for family history and social class had little effect on the results, and including a quadratic term for alcohol intake in the logistic regression provided no evidence of a non-linear association with breast cancer risk (results not shown). 
Table 4 Distribution of participant characteristics by categories of alcohol intake using combined measurement 1

\begin{tabular}{|c|c|c|c|c|c|c|c|c|c|}
\hline & \multicolumn{7}{|c|}{ Alcohol intake (g/day) } & \multirow[t]{2}{*}{$p$ value $^{\mathrm{a}}$} & \multirow{2}{*}{$\begin{array}{l}\text { Number }(\%) \\
\text { missing }\end{array}$} \\
\hline & 0 & $>0$ to $\leq 5$ & $>5$ to $\leq 10$ & $>10$ to $\leq 15$ & $>15$ to $\leq 20$ & $>20$ to $\leq 30$ & $>30$ & & \\
\hline Number of cases/controls & $102 / 374$ & $203 / 626$ & $115 / 331$ & $80 / 212$ & $41 / 127$ & $59 / 116$ & $56 / 119$ & 0.018 & 0 \\
\hline Alcohol intake (g/day) & 0 & $2.3(1.3)$ & $7.3(1.4)$ & $12.4(1.4)$ & $17.4(1.5)$ & $24.0(2.9)$ & $43.2(14.0)$ & - & 0 \\
\hline Age (years) & $60.0(9.1)$ & $57.5(9.1)$ & $56.2(9.3)$ & $56.1(9.5)$ & $54.9(8.8)$ & $55.1(9.2)$ & $53.2(8.7)$ & $<0.001$ & 0 \\
\hline Height (m) & $161.0(6.5)$ & $161.3(6.5)$ & $161.9(6.7)$ & $162.6(6.3)$ & $162.9(6.0)$ & $163.1(6.2)$ & $163.7(6.0)$ & $<0.001$ & $13(0.5 \%)$ \\
\hline Weight (kg) & $68.6(12.8)$ & $68.2(12.6)$ & $66.5(11.2)$ & $66.2(11.2)$ & $65.5(10.1)$ & $66.6(11.3)$ & $68.0(12.4)$ & 0.003 & $27(1.1 \%)$ \\
\hline HRT use $(\%)$ & & & & & & & & 0.001 & $52(2.0 \%)$ \\
\hline Yes & 11.8 & 19.7 & 17.6 & 24.6 & 20.2 & 20.6 & 19.5 & & \\
\hline Physical activity (\%) & & & & & & & & 0.001 & $101(3.9 \%)$ \\
\hline $\operatorname{High}^{\mathrm{d}}$ & 32.0 & 35.8 & 44.1 & 41.9 & 44.2 & 44.9 & 41.2 & & \\
\hline Parity (\%) & & & & & & & & 0.014 & $11(0.4 \%)$ \\
\hline 0 & 19.4 & 18.5 & 19.5 & 18.5 & 21.6 & 20.6 & 32.2 & & \\
\hline 1 & 12.7 & 13.2 & 12.9 & 11.6 & 12.0 & 18.3 & 11.5 & & \\
\hline 2 & 37.1 & 42.6 & 39.1 & 42.1 & 40.1 & 32.6 & 38.5 & & \\
\hline $3+$ & 30.8 & 25.7 & 28.5 & 27.7 & 26.4 & 28.6 & 17.8 & & \\
\hline Menopausal status (\%) & & & & & & & & $<0.001$ & $25(1.0 \%)$ \\
\hline Pre & 10.4 & 14.3 & 21.0 & 22.3 & 21.6 & 24.3 & 30.3 & & \\
\hline Peri & 8.9 & 12.3 & 11.2 & 10.0 & 15.6 & 15.0 & 18.3 & & \\
\hline Post & 80.7 & 73.4 & 67.9 & 67.7 & 62.9 & 60.7 & 51.4 & & \\
\hline Smoking status (\%) & & & & & & & & $<0.001$ & $30(1.2 \%)$ \\
\hline Never & 67.1 & 65.6 & 53.5 & 60.3 & 56.9 & 46.5 & 34.7 & & \\
\hline Former & 23.3 & 25.2 & 35.6 & 31.4 & 32.3 & 43.6 & 48.0 & & \\
\hline Current & 9.6 & 9.2 & 10.9 & 8.3 & 10.8 & 9.9 & 17.3 & & \\
\hline Education level (\%) & & & & & & & & $<0.001$ & $139(5.4 \%)$ \\
\hline $\operatorname{High}^{\mathrm{e}}$ & 32.5 & 39.7 & 47.8 & 55.9 & 55.4 & 63.7 & 62.7 & & \\
\hline Social class (\%) & & & & & & & & $<0.001$ & $434(17.0 \%)^{\mathrm{b}}$ \\
\hline Non-manual & 56.6 & 63.1 & 71.3 & 78.7 & 81.3 & 81.6 & 85.7 & & \\
\hline $\begin{array}{l}\text { Family history of breast } \\
\text { cancer }(\%)\end{array}$ & & & & & & & & 0.211 & $720(28.1 \%)^{\mathrm{c}}$ \\
\hline Yes & 7.1 & 6.6 & 7.9 & 6.8 & 5.3 & 13.4 & 9.9 & & \\
\hline $\begin{array}{l}\text { Total energy intake } \\
\text { (kcal/day) }\end{array}$ & $1677(420)$ & $1712(382)$ & $1744(390)$ & $1798(365)$ & $1855(385)$ & $1865(369)$ & $1976(405)$ & $<0.001$ & 0 \\
\hline Folate intake $(\mu \mathrm{g} /$ day $)$ & $256(82)$ & $257(77)$ & $254(74)$ & $259(73)$ & $252(76)$ & $258(75)$ & $255(79)$ & 0.966 & 0 \\
\hline
\end{tabular}

Results are mean (standard deviation) except where otherwise indicated

${ }^{a}$ For categorical variables $\chi^{2}$ tests were used to test whether the distribution of individuals across categories differed significantly across categories of alcohol intake. For continuous variables the $p$ value is from a one-way analysis of variance

b Social class is missing in EPIC-Oxford

${ }^{c}$ Family history is missing in EPIC-Oxford and Whitehall II

"High physical activity includes those classified as being 'moderately activ" or 'active'. The remainder of individuals were classified as 'inactive' or 'moderately inactive'

${ }^{\mathrm{e}}$ High education level includes individuals who reported education at least up to A-level or equivalent (up to age 17).

\section{Subgroup analyses}

Table 6 shows OR estimates within subgroups according to HRT use, menopausal status and folate intake. There was a significant interaction between alcohol intake and HRT use with the estimated OR per $10 \mathrm{~g} / \mathrm{day}$ increase in alcohol intake being considerably higher and statistically significant among HRT users. Using combined measurement 1 the OR was 1.43 (95\% CI 1.05,1.93) among HRT users and 1.06 (95\% CI 0.97,1.16) among non-users. Combined measurement 2 gave an adjusted OR of 1.59 (1.10-2.30) among HRT users and 1.05 (0.93-1.19) among non-users. Exclusion of the EPIC-Oxford study, in which all individuals in the case-control sample were non-users 
Fig. 2 Adjusted odds ratio estimates per $10 \mathrm{~g} /$ day increase in alcohol intake using combined measurement 1 within studies and the pooled estimate from a fixed-effect meta analysis

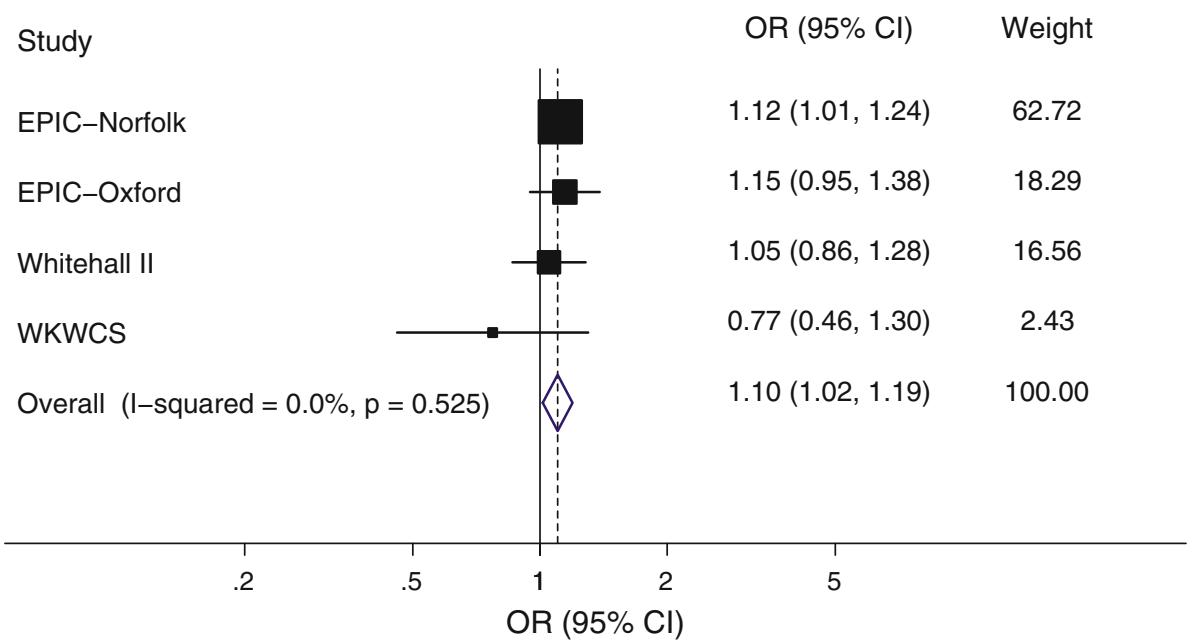

Table 5 Odds ratio (OR) estimates (95\% confidence interval) per $10 \mathrm{~g} /$ day increase in total alcohol intake and in categories of total alcohol intake obtained using diet diary, FFQ, calibrated FFQ, and combined measurements

\begin{tabular}{|c|c|c|c|c|c|}
\hline & Diet diary & FFQ & Calibrated FFQ & $\begin{array}{l}\text { Combined } \\
\text { measurement } 1\end{array}$ & $\begin{array}{l}\text { Combined } \\
\text { measurement } 2^{\mathrm{b}}\end{array}$ \\
\hline \multicolumn{6}{|l|}{ Unadjusted } \\
\hline Per 10 g/day & $1.07(1.00-1.15)$ & $1.15(1.05-1.26)$ & $1.12(1.05-1.20)$ & $1.11(1.03-1.19)$ & $1.10(1.02-1.19)$ \\
\hline \multicolumn{6}{|c|}{ Intake category (g/day) } \\
\hline 0 & $0.85(0.66-1.11)$ & $0.84(0.65-1.08)$ & $0.85(0.65-1.10)$ & $0.84(0.63-1.11)$ & - \\
\hline$>0$ to $\leq 5$ & Ref & Ref & Ref & Ref & - \\
\hline$>5$ to $\leq 10$ & $1.15(0.85-157)$ & $1.15(0.89-1.49)$ & $1.23(0.93-1.61)$ & $1.09(0.83-1.43)$ & - \\
\hline$>10$ to $\leq 15$ & $1.11(0.78-1.60)$ & $1.10(0.79-1.52)$ & $0.88(0.63-1.22)$ & $1.17(0.86-1.61)$ & - \\
\hline$>15$ to $\leq 20$ & $1.03(0.69-1.53)$ & $2.10(1.27-3.47)$ & $1.14(0.78-1.67)$ & $0.96(0.65-1.43)$ & - \\
\hline$>20$ to $\leq 30$ & $0.98(0.68-1.42)$ & $1.23(0.77-1.96)$ & $2.05(1.33-3.16)$ & $1.45(1.01-2.09)$ & - \\
\hline$>30$ & $1.51(1.04-2.18)$ & $1.43(0.87-2.36)$ & $1.40(0.96-2.03)$ & $1.41(0.97-2.03)$ & - \\
\hline \multicolumn{6}{|l|}{ Adjusted $^{a}$} \\
\hline Per 10 g/day & $1.05(0.98-1.13)$ & $1.13(1.02-1.24)$ & $1.10(1.03-1.18)$ & $1.09(1.01-1.18)$ & $1.09(0.99-1.20)$ \\
\hline \multicolumn{6}{|c|}{ Intake category (g/day) } \\
\hline 0 & $0.87(0.66-1.13)$ & $0.84(0.65-1.08)$ & $0.85(0.65-1.12)$ & $0.85(0.64-1.13)$ & - \\
\hline$>0$ to $\leq 5$ & Ref & Ref & Ref & Ref & - \\
\hline$>5$ to $\leq 10$ & $1.20(0.88-1.63)$ & $1.16(0.89-1.509)$ & $1.25(0.95-1.66)$ & $1.12(0.85-1.48)$ & - \\
\hline$>10$ to $\leq 15$ & $1.08(0.75-1.57)$ & $1.09(0.78-1.52)$ & $0.89(0.63-1.25)$ & $1.17(0.85-1.61)$ & - \\
\hline$>15$ to $\leq 20$ & $1.04(0.69-1.55)$ & $2.02(1.21-3.37)$ & $1.12(0.76-1.66)$ & $0.94(0.62-1.42)$ & - \\
\hline$>20$ to $\leq 30$ & $0.95(0.65-1.39)$ & $1.16(0.92-1.15)$ & $1.99(1.27-3.12)$ & $1.44(0.99-2.10)$ & - \\
\hline$>30$ & $1.41(0.96-2.08)$ & $1.31(079-2.19)$ & $1.32(0.89-1.95)$ & $1.31(0.89-1.94)$ & - \\
\hline
\end{tabular}

${ }^{a}$ Adjusted for exact age, parity $(0,1,2,3+)$, height (m), weight $(\mathrm{kg})$, HRT use at date of diary completion (yes/no), physical activity (inactive, moderately inactive, moderately active, active), total energy intake (kcal/day), folate intake ( $\mu \mathrm{g} / \mathrm{day})$, menopausal status (pre, peri, post), smoking (never, former, current), education level (no qualifications, O-level or equivalent (up to age 15), A-level or equivalent (up to age 17), degree level or equivalent), using multiple imputation

${ }^{\mathrm{b}}$ It is not appropriate to estimate ORs within groups using combined measurement 2

of HRT, had little effect on these results. There was no statistically significant difference in the alcohol-breast cancer association by menopausal status or by diet sources of folate intake.

\section{Discussion}

In this study we have been able, for the first time, to compare estimates of the alcohol-breast cancer association 
Table 6 Adjusted odds ratios (95\% confidence intervals) for a $10 \mathrm{~g} /$ day in alcohol intake measured using diet diary, FFQ, calibrated FFQ, and combined measurements in subgroups according to HRT use, menopausal status, and folate intake, all at baseline

\begin{tabular}{|c|c|c|c|c|c|c|}
\hline Subgroup & $\begin{array}{l}\text { Number of } \\
\text { cases/controls }\end{array}$ & Diet diary & FFQ & Calibrated FFQ & $\begin{array}{l}\text { Combined } \\
\text { measurement } 1\end{array}$ & $\begin{array}{l}\text { Combined } \\
\text { measurement } 2\end{array}$ \\
\hline HRT non-users & $532 / 1565$ & $1.03(0.94-1.12)$ & $1.10(0.97-1.24)$ & $1.08(0.99-1.18)$ & $1.06(0.97-1.17)$ & $1.05(0.93-1.19)$ \\
\hline HRT users & $118 / 358$ & $1.43(1.06-1.93)$ & $1.46(0.97-2.21)$ & $1.35(1.01-1.81)$ & $1.45(1.06-1.99)$ & $1.59(1.10-2.30)$ \\
\hline$p$ value & & 0.06 & 0.03 & 0.02 & 0.02 & 0.04 \\
\hline Pre-menopausal & $110 / 360$ & $1.00(0.85-1.18)$ & $1.09(0.85-1.39)$ & $1.07(0.90-1.29)$ & $1.04(0.87-1.24)$ & $1.00(0.80-1.26)$ \\
\hline Peri-menopausal & $113 / 193$ & $1.12(0.82-1.53)$ & $0.98(0.70-1.36)$ & $1.05(0.78-1.40)$ & $0.97(0.65-1.45)$ & $0.97(0.65-1.45)$ \\
\hline Post-menopausal & $423 / 1390$ & $1.08(0.97-1.19)$ & $1.16(1.01-1.33)$ & $1.13(1.02-1.24)$ & $1.12(1.01-1.25)$ & $1.13(1.00-1.29)$ \\
\hline$p$ value & & 0.19 & 0.34 & 0.30 & 0.18 & 0.26 \\
\hline $\begin{array}{l}\text { Tertile } 2 \text { of folate intake } \\
(\geq 217.36 \text { to }<277.45 \mathrm{~g} / \text { day })\end{array}$ & $200 / 654$ & $1.02(0.83-1.26)$ & $1.05(0.80-1.37)$ & $1.06(0.86-1.29)$ & $1.02(0.82-1.27)$ & $0.93(0.71-1.20)$ \\
\hline $\begin{array}{l}\text { Tertile } 2 \text { of folate intake } \\
(\geq 217.36 \text { to }<277.45 \text { g/day })\end{array}$ & $230 / 624$ & $1.05(0.87-1.27)$ & $1.19(0.96-1.48)$ & $1.17(0.99-1.37)$ & $1.14(0.94-1.37)$ & $1.10(0.88-1.38)$ \\
\hline $\begin{array}{l}\text { Tertile } 3 \text { of folate intake } \\
(\geq 277.45 \text { to }<744.71 \mathrm{~g} / \text { day })\end{array}$ & $226 / 627$ & $1.00(0.83-1.21)$ & $1.16(0.86-1.57)$ & $1.12(0.84-1.42)$ & $1.07(0.85-1.34)$ & $1.13(0.88-1.46)$ \\
\hline$p$ value & & 0.17 & 0.17 & 0.13 & 0.14 & 0.16 \\
\hline
\end{tabular}

Adjusted for exact age, parity $(0,1,2,3+)$, height $(\mathrm{m})$, weight $(\mathrm{kg})$, HRT use at date of diary completion (yes/no), physical activity (inactive, moderately inactive, moderately active, active), total energy intake (kcal/day), folate intake ( $\mu \mathrm{g} /$ day), menopausal status (pre, peri, post), smoking (never, former, current), education level (no qualifications, O-level or equivalent (up to age 15), A-level or equivalent (up to age 17), degree level or equivalent), using multiple imputation. $p$-values are from Wald tests

using both diet diary and FFQ measurements of alcohol intake. We investigated the association between prospectively measured alcohol intake and breast cancer in a matched case-control study sampled within four UK cohorts.

Adjusted OR estimates per $10 \mathrm{~g} /$ day of alcohol intake were significantly higher using FFQ compared with diet diary measurements (ORs 1.13 and 1.05). The difference is partly due to lower portion sizes being used to obtain FFQ measurements. Portion sizes used for the diet diary calculations were considered to be more appropriate for intake recorded in the 1990s, as in this study. However, calibration of FFQ measurements, to place them on the same scale as diet diary measurements, gave an adjusted OR (1.10) only a little closer to that found using the diet diary. This suggests that portion sizes do not account for most of the difference between estimates obtained using FFQs and diet diaries. With respect to measuring habitual intake, a major source of error in diet diary measurements is the excess zeros which arise due to episodic consumers, and this may account for a large portion of the apparent attenuation in the diet diary estimates. Both instruments are subject to error from a range of other sources [14]. FFQs are subject specifically to error due to difficulty of recall, lack of information on portion sizes, and omission of food items, though this may not be large problem for alcoholic beverages. Sources of error in short term diet diary measurements include variability in dietary intake over time and lack of detail being provided. Both types of measurement suffer error from selective and mis-reporting. Alcohol may be a particular item which is systematically under-reported [37].

We considered two ways of combining the FFQ and diet diary measurements to make best use of the available data and to go some way towards correcting for measurement error. A particular challenge was how to treat zero measurements. Combined measurement 1 took the average of diet diary and calibrated FFQ measurements, with special treatment of zeros. Combined measurement 2 was the expected true intake conditional on the diet diary and FFQ, calculated by fitting a measurement error model to the data, which required use of a repeated diet diary measurement available in a subset of the EPIC-Norfolk sample. The combined measurements gave adjusted ORs very close to that obtained using the calibrated FFQ (1.11 and 1.09).

Here we discuss what our findings tell us about which instrument or combination of instruments may give the 'best', that is most unbiased, estimate of the association between alcohol intake and breast cancer, or other outcomes. In the absence of a recovery biomarker for alcohol intake, however, it is not possible to draw firm conclusions. Use of a diet diary from one time point appears to clearly result in attenuated OR estimates due to episodic consumers. Correction for error in the diet diary using a measurement error model which accounts both for excess zeros and random error in non-zero measurements gives 
apparently deattenuated results, which is expected [32]. It is important to note that the model used to obtain combined measurement 2 assumes random error in non-zero diary measurements. This assumption has been shown to be invalid in studies of nutrients for which there is a recovery biomarker [16-18], and is thought to typically result in a partial but not complete correction for measurement error. The fitting of the never and episodic consumers measurement error model to obtain combined measurement 2 also makes the assumption that an individual who reports nonzero intake on the FFQ is not a never-consumer, which seems reasonable, but it does not assume that individuals assigned zero intake on the FFQ are necessarily neverconsumers. Combined measurement 1 is a simple and intuitive way of combining both measurements, but has the disadvantage of being ad hoc. In this study we found that using the calibrated FFQ measurement alone, and combined measurements 1 and 2 gave similar OR estimates. However, it is not possible to ascertain whether this finding should persist across other studies. What is clear from this study is that investigators should take care to assign appropriate portion sizes for use in programs designed to obtain both FFQ and diet diary measurements and be aware that too-low portion sizes can result in spuriously high associations. Obtaining more detailed information about typical portion sizes, for example from weighed food records, seems to be important if more firm conclusions about the effects of alcohol on disease risk are to be made. However, this may not be possible retrospectively because typical portion sizes for alcohol may have changed over time.

Strengths of our study include the use of a common program (DINER) to obtain most diet diary measurements, data on a large number of potential confounders, and the availability of repeated diet diary measurements. Our study also has some limitations. Potential confounders were assessed at baseline and it was not possible to investigate the effect of potential effect modifiers closer to diagnosis. Alcohol intake was also assessed only at one time point. We were unable to investigate whether the association between alcohol and breast cancer differed according to tumour subtypes and hormone receptor status $[6,9,10,12$, 38 ] and there was insufficient data to investigate the effect of different alcohol beverages [8, 39, 40].

Previous studies have been based on questionnaire measurements of alcohol intake. The Million Women Study recently found a relative risk of 1.12 (95\% CI 1.09, 1.15 ) for a $10 \mathrm{~g} /$ day increase in alcohol intake based on 22,000 cases among drinkers [2]. Meta analyses have found combined OR or relative risk estimates per $10 \mathrm{~g} /$ day increase in alcohol intake of 1.09 (95\% CI 1.04, 1.13) [8], $1.071(95 \%$ CI $1.055,1.087)$ [3], and $1.11(95 \%$ CI 1.05,1.15) [5]. A meta-analysis of data from 10 countries in
EPIC-Europe found a much smaller overall estimated incidence rate ratio of 1.03 (95\% CI 1.01, 1.05) per $10 \mathrm{~g} /$ day increase in alcohol intake, also using questionnairebased data [41]. Some studies have suggested that the association between alcohol intake and breast cancer risk may be modified by HRT use [42]; menopausal status [43, 44]; and folate intake [45-47]. In our results the association was significantly larger among women who reported using HRT at baseline compared with non users. However, neither the Million Women Study [2] nor the EPIC-Europe study [41] found evidence of any interaction by HRT use and further studies using information about use over time are encouraged. We found no evidence of differences in the association by dietary folate intake or menopausal status.

In summary, our results indicate an increased risk of breast cancer even for a small increase in daily alcohol intake, with an estimated $10 \%$ increase per $10 \mathrm{~g} /$ day increase in alcohol intake. This is broadly in agreement with results from previous studies. Our study provides evidence that the association is likely to be underestimated using a diet diary measurement from one time point.If using only one measurement, a FFQ would be preferred over a diet diary on the basis of these results, provided the FFQ measurements are based on appropriate portion sizes. Further investigations are needed to investigate what, if anything, a combination of both measurements, or use of repeated two or more diet diary measurements, can offer over a single FFQ measurement. However, common sense suggests that two measurements should be better than one in general, provided they are appropriately combined.

Acknowledgments Professor Sheila Rodwell (known professionally as Sheila Bingham) who died in 2009 established the UK Dietary Cohort Consortium as part of the MRC Centre for Nutritional Epidemiology and Cancer of which she was Director. Ruth Keogh and Ian White were supported by the Medical Research Council [Unit Programme number U105260558]. The Medical Research Council also funds the UK Dietary Cohort Consortium at the MRC Centre for Nutritional Epidemiology in Cancer Prevention and Survival. The cohort studies included in this consortium received funding from: British Heart Foundation; Cancer Research UK; Department of Health, UK; Food Standards Agency, UK; Medical Research Council, UK; the Stroke Association, UK, and the World Cancer Research Fund.

Open Access This article is distributed under the terms of the Creative Commons Attribution License which permits any use, distribution, and reproduction in any medium, provided the original author(s) and the source are credited.

\section{References}

1. Ferlay J, Shin HR, Bray F, Forman D, Mathers C, Parkin DM. Estimates of worldwide burden of cancer in 2008: GLOBOCAN 2008. Int J Cancer. 2010;127:2893-917. 
2. Allen NE, Beral V, Casabonne D, et al. Moderate alcohol intake and cancer incidence in women. J Natl Cancer Inst. 2009;101: 296-305.

3. Collaborative Group on Hormonal Factors in Breast Cancer. Alcohol, tobacco and breast cancer-collaborative reanalysis of individual data from 53 epidemiological studies, including 58515 women with breast cancer and 95067 women without the disease. Br J Cancer. 2002;87:1234-45.

4. Ellison RC, Zhang Y, McLennan CE, Rothman KJ. Exploring the relation of alcohol consumption to risk of breast cancer. Am $\mathbf{J}$ Epidemiol. 2001;154:740-7.

5. Key J, Hodgson S, Omar RZ, et al. Meta-analysis of studies of alcohol and breast cancer with consideration of the methodological issues. Cancer Causes Control. 2006;17:759-70.

6. Lew JQ, Freedman ND, Leitzman MF, et al. Alcohol and risk of breast cancer by histologic type and hormone receptor status: the NIH-AARP diet and health study. Am J Epidemiol. 2009;170: 308-17.

7. Longnecker MP. Alcoholic beverage consumption in relation to risk of breast cancer: meta-analysis and review. Cancer Causes Control. 1994;5:73-82.

8. Smith-Warner SA, Spiegelman D, Yaun SS, et al. Alcohol and breast cancer in women: a pooled analysis of cohort studies. JAMA. 1998;279:535-40.

9. Suzuki R, Ye W, Rylander-Rudqvist T, Saji S, Colditz GA, Wolk A. Alcohol and postmenopausal breast cancer risk defined by estrogen and progesterone receptor status: a prospective cohort study. J Natl Cancer Inst. 2005;97:1601-8.

10. Suzuki R, Orsini N, Mignone L, Saji S. Wolk A. Alcohol intake and risk of breast cancer defined by estrogen and progesterone receptor status. A meta-analysis of epidemiological studies. Int $\mathbf{J}$ Cancer. 2008;122:1832-41.

11. WCRF/AICR. Food, nutrition, physical activity, and the prevention of cancer: a global perspective. Washington DC: AICR; 2007.

12. Zhang SM, Lee IM, Manson JE, Cook NR, Willett WC, Buring JE. Alcohol consumption and breast cancer risk in the women's health study. Am J Epidemiol. 2007;165:667-76.

13. Baan R, Straif K, Grosse Y, et al. Carcinogenicity of alcoholic beverages. Lancet Oncol. 2007;8:292-3.

14. Willett W. Nutritional epidemiology. 2nd ed. Oxford: Oxford University Press; 1998.

15. Freedman LS, Schatzkin A, Midthune D, Kipnis V. Dealing with dietary measurement error in nutritional cohort studies. J Natl Cancer Inst. 2011;103:1086-92.

16. Day NE, McKeown N, Wong MY, Welch A, Bingham S. Epidemiological assessment of diet: a comparison of a 7-day diary with a food frequency questionnaire using urinary markers of nitrogen, potassium and sodium. Int J Epidemiol. 2001;30:309-17.

17. Kipnis V, Subar AF, Midthune D, et al. Structure of dietary measurement error: results of the OPEN biomarker study. Am J Epidemiol. 2003;158:14-21.

18. Schatzkin A, Kipnis V, Carroll RJ, et al. A comparison of a food frequency questionnaire with a 24-h recall for use in an epidemiological cohort study: results from the biomarker-based observing protein and energy nutrition (OPEN) study. Int J Epidemiol. 2003;32:1054-62.

19. Dahm CC, Keogh RH, Spencer EA, et al. Dietary fiber and colorectal cancer risk: a nested case-control study using food diaries. J Natl Cancer Inst. 2010;102:614-26.

20. Bingham SA, Luben R, Welch A, Wareham N, Khaw KT, Day N. Are imprecise methods obscuring a relation between fat and breast cancer? Lancet. 2003;362(9379):212-4.

21. Freedman LS, Potischman N, Kipnis V, et al. A comparison of two dietary instruments for evaluating the fat-breast cancer relationship. Int J Epidemiol. 2006;35(4):1011-21.
22. Key TJ, Appleby PN, Cairns BJ, et al. Dietary fat and breast cancer: comparison of results from food diaries and food-frequency questionnaires in the UK Dietary Cohort consortium. Am J Clin Nutr. 2011;94:1043-52.

23. Bingham SA, Welch AA, McTaggart A, et al. Nutritional methods in the European prospective investigation of cancer in Norfolk. Public Health Nutr. 2001;4:847-58.

24. Brunner E, Stallone D, Juneja M, Bingham S, Marmot M. Dietary assessment in Whitehall II: comparison of 7 day diet diary and food-frequency questionnaire and validity against biomarkers. $\mathrm{Br}$ J Nutr. 2001;86:405-14.

25. Cade JE, Burley VJ, Greenwood DC. The UK women's cohort study: comparison of vegetarians, fish-eaters and meat-eaters. Public Health Nutr. 2004;7:871-8.

26. Davey GK, Spencer EA, Appleby PN, Allen NE, Knox KH, Key TJ. EPIC-Oxford: lifestyle characteristics and nutrient intakes in a cohort of 33883 meat-eaters and 31546 non meat-eaters in the UK. Public Health Nutr. 2003;6:259-69.

27. Day N, Oakes S, Luben R, et al. EPIC-Norfolk: study design and characteristics of the cohort. European prospective investigation of cancer. Br J Cancer. 1999;80(Suppl 1):95-103.

28. Marmot M, Brunner E. Cohort profile: the Whitehall II study. Int J Epidemiol. 2005;34:251-6.

29. Wadsworth M, Kuh D, Richards M, Hardy R. Cohort profile: the 1946 National Birth Cohort (MRC National Survey of Health and Development). Int J Epidemiol. 2006;35:49-54.

30. Welch AA, McTaggart A, Mulligan AA, et al. DINER (Data Into Nutrients for Epidemiological Research) - a new data-entry program for nutritional analysis in the EPIC-Norfolk cohort and the 7-day diary method. Public Health Nutr. 2001;4: 1253-65.

31. Cade JE, Frear L, Greenwood DC. Assessment of diet in young children with an emphasis on fruit and vegetable intake: using CADET - child and diet evaluation tool. Public Health Nutr. 2006;9:501-8.

32. Keogh RH, White IR. Allowing for never and episodic consumers when correcting for error in food record measurements of dietary intake. Biostatistics. 2011;12:624-36.

33. Rosner B, Willett WC, Spiegelman D. Correction of logistic regression relative risk estimates and confidence intervals for random within-person measurement error. Am J Epidemiol. 1992; 136:1400-13.

34. Higgins JP, Thompson SG. Quantifying heterogeneity in a metaanalysis. Stat Med. 2002;21:1539-58.

35. Royston P. Multiple imputation of missing values: update. Stata J. 2005;5:188-201.

36. Carlin JB. A new framework for managing and analyzing multiply imputed data in Stata. Stata J. 2008;8:49-67.

37. Single E, Wortley S. A comparison of alternative measures of alcohol consumption in the Canadian National Survey of alcohol and drug use. Addiction. 1994;89:395-9.

38. Li CI, Chlebowski RT, Freiberg MD, et al. Alcohol consumption and risk of postmenopausal breast cancer by subtype: the women's health initiative observational study. J Natl Cancer Inst. 2010;102:1422-1431.

39. Newcomb PA, Nichols HB, Beasley JM, et al. No difference between red wine or white wine consumption and breast cancer risk. Cancer Epicur Bio Prev. 2009;18:1007-10.

40. Viel JF, Perarnau JM, Challier B, Faivre-Nappez I. Alcoholic calories, red wine consumption and breast cancer among premenopausal women. Eur J Epidemiol. 1997;13:639-43.

41. Tjønneland A, Christensen J, Olsen A, et al. Alcohol intake and breast cancer risk: the European prospective investigation into cancer and nutrition (EPIC). Cancer Causes Control. 2007;18: 361-73. 
42. Nielsen NR, Gronbaek M. Interactions between intakes of alcohol and postmenopausal hormones on risk of breast cancer. Int $\mathbf{J}$ Cancer. 2008;122:1109-13.

43. Reichman ME, Judd JT, Longcope C, et al. Effects of alcohol consumption on plasma and urinary hormone concentrations in premenopausal women. J Natl Cancer Inst. 1993;85: $722-7$.

44. Singletary KW, Gapstur SM. Alcohol and breast cancer. JAMA. 2001;286:2143-51.
45. Rohan TE, Jain MG, Howe GR, Miller AB. Dietary folate consumption and breast cancer risk. J Natl Cancer Inst. 2000;92: 266-9.

46. Zhang S, Hunter DJ, Hankinson SE, et al. A prospective study of folate intake and the risk of breast cancer. JAMA. 1999;281: 1632-7.

47. Sellers TA, Kushi LH, Cerhan JR, et al. Dietary folate intake, alcohol, and risk of breast cancer in a prospective study of postmenopausal women. Epidemiology. 2001;12:420-8. 